\title{
Community design and how much we drive
}

\author{
Wesley E. Marshall \\ University of Colorado Denver a
}

\author{
Norman W. Garrick \\ University of Connecticut ${ }^{b}$
}

\begin{abstract}
The preponderance of evidence suggests that communities with denser and more connected street networks and a higher degree of mixed land uses results in fewer vehicle kilometers traveled (VKT). However, there is less agreement on the size of the effect. Also, there is no clear understanding of the specific aspects of community design—such as street networks and land use mix — that are most important in contributing to lower VKT. One reason why there is some confusion on this point is that past studies have not always made a clear distinction between different street network design characteristics such as density, connectivity, and configuration. In this research, care was taken to control for land use mix while fully characterizing the different features of the street network, including a street pattern classification system that works at the neighborhood level but also focuses on the citywide street network as a separate entity.

We employ a spatial kriging analysis of National Household Travel Survey (NHTS) data in combination with a generalized linear regression model in order to examine the extent to which community design, particularly in terms of street network design while controlling land use mix, influences VKT in 24 California cities of populations from 30,000 to just over 100,000. Our results suggest that residents of more compact street network designs tend to drive less. Street connectivity, however, played an adverse role in performance.
\end{abstract}

\section{Introduction}

From the end of the Second World War up until the recent economic downturn, vehicle kilometers traveled (VKT) in the United States had been consistently increasing at a dramatic rate. In fact, VKT growth has outpaced population growth in this country by a factor of nearly 10 to 1 over the course of much of the last century, as Figure 1 illustrates (adapted from Moeller 1992). Due to this widespread growth in travel demand, the U.S. must contend with multiple issues including record high traffic congestion that wastes both time and gasoline to the extent of 4.2 billion hours and more than 10 billion liters (2.8 billion gallons) of gasoline in 2007 (Schrank and Lomax 2009). While the Urban Mobility Report asserts that this wasted time and gasoline plagues the U.S. economy by more than $\$ 87$ billion a year-a 50 percent increase from the late 1990s - the amount of driving by Americans also requires the U.S. to import 1.9 billion liters (500 million gallons) of crude oil each day, 40 percent of which is dedicated to the transportation sector at a cost of more than $\$ 180$ billion each year (Schrank and Lomax 2009; U.S. Energy Information Administration 2010). Even without delving into broader envi-

a wesley.marshall@ucdenver.edu

bnorman.garrick@uconn.edu ronmental implications, excessive driving continues to strain the U.S. both at home and abroad. For these reasons, researchers and policymakers persistently look for ways to reduce vehicle dependency so that our cities can become more sustainable and more resilient to anticipated increases in oil prices. Despite the fact that numerous factors likely contribute to these driving trends, many transportation professionals attribute the increases in VKT partly to the evolution of community design, particularly in terms of street network design and land uses, over the last 60 years.

American communities during the first half of the 20th century were typically composed of heterogeneous land uses built on dense, fully connected streets most often laid out in a gridded configuration; however, from the late 1940s though the 1990s, almost every new community began to segregate land uses and featured a tree-like, hierarchical, cul-de-sac layout (Southworth and Ben-Joseph 1997). While noting the changes in the arrangement of land uses and network configuration is important, it is also worth recognizing the accompanying reductions in density; in other words, the newer communities became increasingly sparser and spread out (Southworth and Ben-Joseph 1997; Taylor 2001). Therefore, it is likely not a coincidence that this time period overlapped with the sharp rise in VKT in the United States. Figure 1 illustrates this evolution 
in community design in terms of street network changes over the time period that corresponds to the run-up in VKT.

A number of factors helped guide this evolution in community design; one of the more interesting was the role played by the Federal Housing Authority (FHA). Even before transportation engineers and urban planners began recommending community designs based on street networks with hierarchical street layouts in the 1950s, the FHA had already released two technical bulletins in the 1930s advocating the use of cul-desac layouts and describing the more traditional gridded street networks as monotonous, with little character or appeal, uneconomical, and posing a safety issue (Southworth and BenJoseph 1997). These bulletins became part of the design criteria that the FHA used in overseeing and financing more than 22 million properties in just 15 years, and eventually became the basis for many zoning and land use regulations requiring homogeneous land uses (Southworth and Ben-Joseph 1997).

Today, more traditional community designs with gridded street network and mixed land use configurations are increasingly being seen as key ingredients in supporting transportation options beyond private vehicles. While there is growing evidence to support the belief that such community designs support walking, biking, and transit, many investigators continue to assert that the supposed advantages are overstated. Also, there is no clear understanding of the specific aspects of community design that most contribute to lower VKT. One reason why there is some confusion on this point is that past studies have not always clearly identified the various aspects of community design in terms of features such as street network characteristics or street design elements. In our study, care was taken to fully characterize the three main distinguishing factors in street network design: density, connectivity, and configuration, as well as a number of street design features such as the number of lanes, sidewalks, bicycle lanes, and the presence of medians or on-street parking. In determining how these community design factors, in terms of street network and street design, relate to the amount of driving done by the people living in those communities, we also controlled for the degree of mixed land uses, proximity to the city center, and the presence of a limited-access highway. The study was based on data from 24 medium-sized California cities with populations from 30,000 to just over 100,000. With National Household Travel Survey (NHTS) VKT data, we performed a spatial kriging analysis at the U.S. Census block group level of geography, along with a generalized linear regression model in order to explicitly quantify the extent of the range of community design effects on VKT.

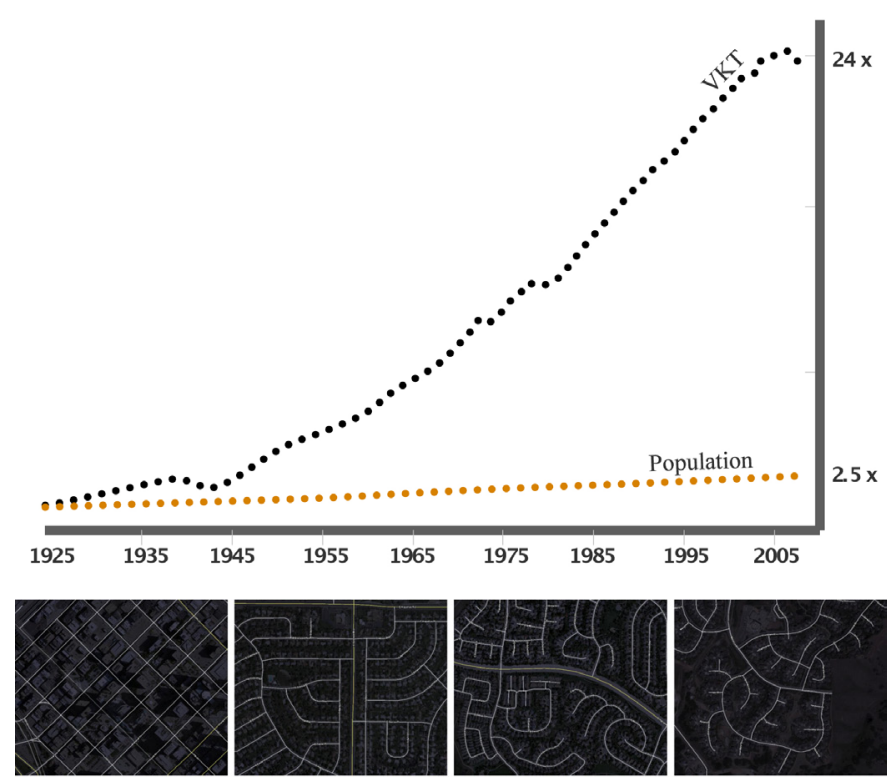

Figure 1 VKT, population (1925-2008), and the evolution of community design in terms of street networks in the US. VKT data derived from FHWA and Moeller (1992).

\section{$2 \quad$ Literature Review}

The effect of community design on travel behavior-in terms of travel demand, travel patterns, and mode choice- - has increasingly become the subject of academic research over the last few decades. While the preponderance of evidence suggests that denser communities with mixed land uses and denser, more connected street networks result in lower VKT, there is much less agreement on the size of the effect and the role of the various community design elements. At the same time, a handful of studies have found no significant association between community design and VKT; in fact, some researchers speculate that while denser and more connected communities might result in shorter trips and more trips by active transportation means, they might also result in more overall trips and no VKT reductions. The intent of this literature review is to take a closer look at this body of research - in particular with respect to the community design matters of street network density, street connectivity, network configuration, and street design features while also controlling for the mix of land uses - to help understand why, despite the attention this topic has received, many questions remain unresolved.

The earliest studies that focused on community design in terms of street network characteristics were simulationbased and rarely relied on specific field measurements or surveys. Curtis et al., in the mid-1980s, modeled differences in the amount of fuel used for hierarchical, tree-like configura- 
tions against hypothetical gridded and fully connected street designs. Holding density and land use constant, he estimated that communities with more traditional street designs would save as much as 30 percent in fuel costs (Curtis, Neilsen et al. 1984). Walter Kulash, in the early 1990s, performed a similar simulation study and found a 57 percent decrease in VMT for neighborhood travel (Kulash 1990).

Empirical studies seemed to find similar trends; however, the magnitude of the differences tended to be much smaller than those found with the simulation studies. For instance, a study by the Portland Metro found that increasing street connectivity in a community from a low to a moderate level reduced trip length by 2 percent, vehicle delay by 14 percent, and VMT by 2 percent (Portland Metro 2004 ; Litman 2005). The Puget Sound Regional Council took street network density into account and found that VMT dropped by 0.5 percent for every 10 percent increase in intersections per mile in the King County, Washington, area. Cervero and Gorham took both density and street connectivity into account and found that community designs with more traditional street networks and land use mixes had much higher pedestrian mode shares than more modern "automobile-oriented neighborhoods" (Cervero and Gorham 1995). In a later study, Cervero and Kockelman not only found increased non-automobile mode shares to be associated with denser developments, but also that more traditionally gridded communities, combined with parking restrictions, resulted in the most substantial mode shift toward active transportation and the largest VKT reductions (Cervero and Kockelman 1997).

Frank et al. extended this linkage between community design and travel behavior to vehicle emissions with a study in the Seattle region (Frank Jr. et al. 2000). While the study found that community designs with more traditional street networks resulted in more trips of all types, the results also suggested a decrease in overall VKT and a corresponding reduction in vehicle emissions. The increase in trips was offset by the fact that street networks with higher street connectivity also had more walking, biking, and transit trips. These results are consistent with an influential study by Newman and Kenworthy that charted overall fuel consumption in 32 worldwide cities measured against the population density of these places (Newman and Kentworthy 1989). They found a distinct relationship between fuel consumption and community density, with fuel consumption decreasing as the density of the city increased. Newman furthers this examination in a later study of energy use and urban form by examining the New York City and San Francisco regions in more detail (Newman and Kentworthy 1989). In both locations, the amount of gasoline used increased exponentially with decreased density, moving from the central city towards the outer suburbs where the maximum amount of energy was used. While these comparisons do not reveal what specific differences in urban form and travel patterns account for this relationship to fuel consumption, the trends are worthy of note and would likely be indicative of similar trends in VKT per capita.

However, not all of the literature found such community design measures to be significant factors in affecting travel behavior. A study by Mindali et al. reviewed the results of Newman and Kenworthy using a multivariate statistical technique and found no evidence of a statistically significant relationship between density and energy consumption (Mindali, Raveh et al. 2004). The authors attributed a portion of the divergence in results to data validity issues relating to the age of the data and the survey instrument used, but reserved much of their criticism for Newman and Kenworthy failing to adequately differentiate between central business district densities and outer area densities together with employment and population densities. When these variables are appropriately accounted for, Midali et al. report that population density has no significant correlation with energy consumption. Another study by Holdzclaw showed that the configuration of a community in terms of street patterns had no significant effect on total VKT per household (Holtzclaw 1994). Crane went on to suggest that the transportation benefits of denser and more connected communities are being over-quantified because, while improved accessibility decreases trip distances, it also increases trip frequencies and overall travel in the transportation system (Crane 1996). Also, a recent study by Su found that while increased population density had a negative correlation with travel demand, increasing the density of the road network had the opposite effect, resulting in higher VKT (Su 2010).

A common problem with much of the existing research is failure to fully characterize community designs in terms of the differences in street networks. For instance, there is a preponderance of academic literature focused more on land uses without specifically taking into account the full array of street network measures. Much of the research is in agreement that more compact regions result in lower VKT per capita, and a recently conducted meta-analysis of 62 regional scenario planning efforts found that continually developing toward a more compact land use-transportation scenario $(-19$ percent greater density than current forms) could reduce driving by 17 percent by 2050 (Ewing, Pendall et al. 2003; Bartholomew and Ewing 2009). More relevant to this particular study is a recent evaluation of the potential of land use changes to reduce VKT specific to California. The results suggest that a 10 percent increase in residential density would result in only a 1.9 percent decrease in driving (Heres-Del-Valle and Niemeier 2011). While these 
studies represent only a small subset of the literature focused on land use and VKT, it was atypical to see street network design specifically taken into account. Of the papers that did account for street network design, most focused solely on factors such as street connectivity, while others looked more at density or compactness; moreover, the existing research rarely took into account street configuration in a measurable way. For instance, Crane, in a study with Crepeau, found no evidence that street configuration influenced differences in walking or driving for non-work trips; however, they did not explicitly consider network density (Crane and Crepeau 1998). Also, Su conducted her study at a relatively high level of geography, which made it too difficult to account for street configuration or even connectivity.

Since precise measures of street network factors were fairly uncommon, other studies simply separated communities into very basic categories such as "sprawl" and "smart growth." Unfortunately, such a broad perspective makes untangling the complexities of the factors influencing VKT even more challenging. For these reasons, in our study we look to fully characterize the differences in community design in terms of street network factors such as density, connectivity, and configuration, while also taking into account street design features and the relative mix of land uses, in order to establish a clearer picture of how the full range of street network characteristics might influence the amount of driving we do. The next section describes the community design measures we employed and how they can be effectively teamed with a visual system for classifying street network configurations.

\section{Characterizing Community Design and Street Networks}

Many urban designers, planners, and engineers point to increased density and connectivity as desirable qualities. In fact, a handful of governments (including the Commonwealth of Virginia) have adopted measures for street connectivity as part of their zoning, land use, and subdivision ordinances. However, such regulations can be very difficult to craft effectively since communities evolve in such a wide variety of shapes and sizes, and there is unfortunately not one commonly accepted method of quantifying the preferred layouts.

In terms of community design differences, this research effort focuses on characterizing street network characteristics, which can generally be described by three factors: density, connectivity, and configuration. While intersection density, deadend density, centerline kilometer density, and average block size comprise some of the more common indices of street network density, the link-to-node ratio and the connected-node ratio are common connectivity indices. Intersection density is typically calculated by the number of intersections per unit area, most often a square kilometer or square mile. Overall intersection density includes the total number of nodes or intersections, including dead ends. For the link-to-node ratio, the number of links (road segments between intersections) is divided by the number of nodes (or intersections) (Ewing 1996; Litman 2005). The node count is typically represented by the total number of intersections including dead ends. As a result, a higher number of dead ends effectively reduces the link-to-node ratio of the network; accordingly, the higher the link-to-node value, the more connectivity. Most researchers and practitioners state that a score of 1.4 generally indicates high connectivity (Handy, Paterson et al. 2003; Litman 2005). The connected-node ratio (CNR) is the ratio of non-dead-end intersections over the total number of intersections including dead ends (Handy, Paterson et al. 2003). Ultimately, intersection density and the link-to-node ratio were selected to represent density and connectivity because they were deemed the strongest measures of street network density and connectivity, respectively, by repeated statistical analyses in our dataset.

One ongoing problem with the aforementioned measures remains basic terminology. It is not uncommon, even for experts, to focus on connectivity, when such a discussion is often intended to be shorthand for a more compact community. However, basic connectivity measures such as the link-to-node ratio give little information as to the density of a community. For instance, traditional community designs based on a gridded street network configuration are characteristically highly connected, but without additional information, there is no way to tell whether the grid covers one square kilometer or one hundred square kilometers. At the same time, it is not uncommon to see a density measure, such as intersection density, used as a proxy for street connectivity. Figure 2 illustrates the difficulties that using such measures interchangeably can cause.

Another issue with the general approach in the literature to characterizing street networks is that most fail to impart any sense of configuration. Some more advanced measures— such as space syntax, measurements based on graph theory, or John Peponis' concepts of Reach and Directional Distance-can provide valuable information, but such measures are often difficult to calculate, interpret, and visualize (Hillier and Hanson 1984; Jiang and Claramunt 2004; Ratti 2004; Marshall 2005; Peponis Allen et al. 2007; Raford, Chiaradia et al. 2007). As a result, we devised a straightforward methodology for classifying street patterns, adapted from Stephen Marshall's book Street and Patterns, that emphasizes the structure of the macro-level street network (or citywide network in our own vernacular) separately from the micro-level street network (or neighbor- 
hood network) (Marshall 2005). While arterial and collector roads are based on the functional classification system and generally differ from local roads in terms of specific elements such as the number of lanes, lane widths, and traffic volumes, the macro-level network in this case is classified strictly based on the role of the street in terms of network structure. This difference between functional classification and network structure allows us to better convey some of the complexities that distinguish communities, in particular the difference between neighborhood and citywide connectivity, and the relative density and connectivity of those elements. For instance, intersection density can be broken down by intersection type based on the corresponding intersecting nodes, such as citywide street network intersections (the intersection of two citywide streets).

Although Marshall's system of four citywide categories and two neighborhood categories does not accommodate every configuration possible, it does create a straightforward and transferable visual classification system for the relative differences in the most common types of street network configurations. In terms of application, the system is fairly simple and intuitive; however, at this point, it remains a manual procedure as depicted in Figure 3 at both the city scale and neighborhood scale for San Mateo, California. The initial step is to select the streets that are generally continuous across a substantial portion of the city and designate those as the citywide streets. This process and being able to visualize the citywide streets helps facilitate the classification of each block group into one of the eight representative configuration types. Real-world city patterns are often curvilinear or generally more complex than the exemplary configurations, so while actual street networks are not always exactly as shown in the diagram, there were only a handful out of the more than 1,000 block groups that could not be confidently classified. That subset of block groups was removed from the statistical analysis. Combining the street network density and connectivity measures described earlier with configuration types results in a more complete understanding of street networks than can conventionally be achieved using functional classification.

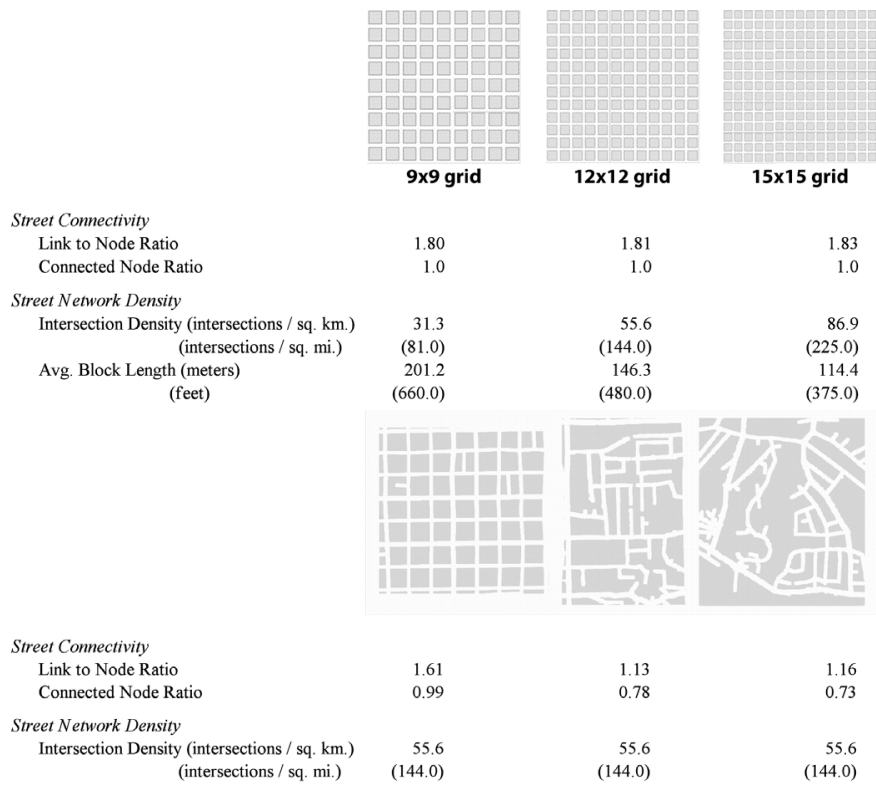

Figure 2 Distinguishing indices representing street connectivity and street network density.

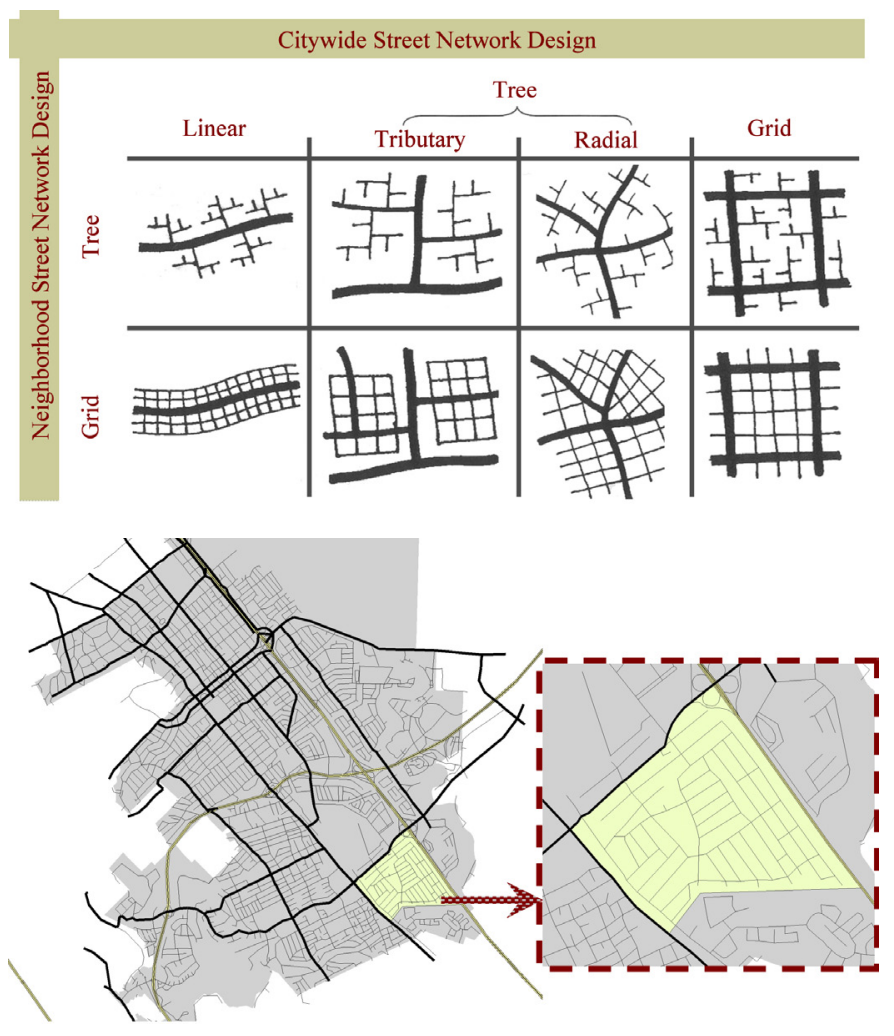

Figure 3 Citywide vs. neighborhood street network classification system (adapted from Stephen Marshall 2005) and close-up for San Mateo, Calif. 


\section{$4 \quad$ Overview of Study}

This research is based on an initial database for a road safety study of 473 California cities. California became the focus in order to maintain consistency in crash severity outcomes and because of the large number and diversity of city types. This diversity in city types and transportation systems is the same quality that makes these cities suitable for a study on VKT and community design. For the previous study, we selected 24 cities for a more detailed analysis based, in part, on overall traffic fatality rates. However, we also considered, to the extent possible, geography balance and factors such as compatibility in terms of population and average income. The selected cities are:
- Alameda
- Antioch
- Apple Valley
- Berkeley
- Carlsbad
- Chico
- Cupertino
- Danville
- Davis
- La Habra
- Madera
- Morgan Hill
- Palo Alto
- Perris
- Redding
- Rialto
- San Luis Obispo
- San Mateo
- Santa Barbara
- Santa Cruz
- Temecula
- Turlock
- Victorville
- West Sacramento

\subsection{Description of community design data}

\section{Street network data}

The street network GIS data were derived from a number of sources including U.S. Census TIGER line files, the California Spatial Information Library, and the California Department of Transportation (CalTrans) records. The community design measures for characterizing the street networks were calculated using ArcGIS at the census block group level of geography. With regard to the edge effects, such as intersection nodes or street segments sitting on the border of multiple block groups, we counted those points and/or segments toward each of the bordering block groups. While this means the block group data cannot be aggregated, it results in a fairer comparison than the other options of either assigning the point or segment to a single block group or counting them toward none of the block groups. Census data from the year 2000-including mode shares, travel time to work, household income levels, and demographic information - were collected and analyzed. We also collected the following design characteristics for every citywide street segment (based on the street categorization methodology discussed earlier) using field measurements in addition to Google Earth and Google Street View:

- Total number of lanes

- Curb-to-curb distance

- Outside shoulder width

- Inside shoulder width (when median present)

- Raised median width

- Painted median width

- On-street parking $(0=$ no, $1=$ yes, $0.5=$ along one side of street)

- Bike lanes $(0=$ no, $1=$ yes, $0.5=$ along one side of street)

- Curbs $(0=$ no, $1=$ yes, $0.5=$ along one side of street $)$

- Sidewalks $(0=$ no, $1=$ yes, $0.5=$ along one side of street)

\section{Land use data}

In order to quantify the degree of mixed land uses of the more than 1,000 block groups in 24 cities, we employed a ratio of proxy variables based on population and employment. These proxy variables were estimated based on the relative levels of population and employment in each zone compared to every other zone in the city while also accounting for the distance between zones in order to better judge the overall level of population and employment in the vicinity of a zone rather than that just in the zone itself. Adapted from an exposure metric developed by Graham and Glaister, these equations are used to calculate the population and employment levels in the vicinity of a particular zone for a simplified gravity model as follows (Graham and Glaister 2003; Noland and Quddus 2004): 


$$
\begin{gathered}
\mathrm{PE}_{i}=\sum_{j} \frac{\mathrm{E}_{j}}{\mathrm{~d}_{i j}} \quad \mathrm{PP}_{i}=\sum_{j} \frac{\mathrm{P}_{j}}{\mathrm{~d}_{i j}} \\
\mathrm{M}_{i}=\frac{\mathrm{PE}_{i}}{\mathrm{PP}_{i}}
\end{gathered}
$$

In the above equations, $\mathrm{PE}_{i}$ represents the employment proximate to block group $\mathrm{i}$ and $\mathrm{PP}_{i}$ the population proximate to block group i. $\mathrm{P}_{j}$ is the level of population, $\mathrm{E}_{j}$ is the level of employment, and $\mathrm{d}_{i j}$ is the centroid-to-centroid distance between zones within each city. The centroid-to-centroid distances are calculated in terms of feet, with a distance of 1 foot used to calculate the intra-zone proxy values. Overall, $\mathrm{PE}_{i}$ and $\mathrm{PP}_{i}$ generally characterize relative accessibility, while $\mathrm{M}_{i}$ represents the degree of mixed land uses in the vicinity of block group i. Although the resulting numerical values are not particularly useful for a single block group, the metrics are useful in characterizing relative accessibility and the degree of mixed land uses in comparison to all other block groups and serve as a valuable proxy.

Proximate population and proximate employment both turned out to be highly correlated with other variables, such as intersection density, but not as significant in the models and thus not used. Other land use variables taken into account include the block group's distance from the city center and a binary variable indicating whether or not a limited access highway bisects or is adjacent to the zone.

\section{National Household Travel Survey (NHTS) data}

Data from the 2001 NHTS travel survey were collected at the census tract level of geography. These data included the number of households grouped by household size, the number of vehicles owned, the number of vehicle kilometers traveled per household per weekday, the number of vehicle trips per household per weekday, as well as the percent of trips that were home-based work, home-based shopping, home-based socialrecreational, and home-based other trips. Using these data, we calculated VKT per person 18 years old or older per day based on a weighted average, which accounted for the number of households surveyed within each household size grouping and safeguarded from potentially oversampled populations controlling the results.

\subsection{Statistical methodology}

The statistical analysis was conducted at the U.S. Census block group level of geography. According to the U.S. Census, a block group averages between 250 and 500 housing units and varies in area depending on housing density. The 24 cities in this study combined had more than 1,000 distinctly populated block groups at an average of approximately 43.5 block groups per city. In order to best generate estimated VKT values at the block group level rather than the census tract level collected by NHTS, we employed spatial kriging, which is an advanced geostatistical ArcGIS spatial interpolation procedure. Kriging differs from basic interpolation methods such as inverse distance weighted (IDW) or spline interpolation in that, rather than base interpolations on surrounding measured values, kriging develops a statistical model that takes into account autocorrelation and the overall spatial arrangement of the points (Oliver 1990). Ordinary kriging was selected because there was no basis for rejecting it in exchange for universal kriging, which would only be applicable when there is a known trend in the data. The general equation for ordinary kriging is as follows:

$$
\mathrm{Z}\left(\mathrm{s}_{0}\right)=\sum_{t=1}^{\mathrm{N}} \lambda_{i} Z\left(s_{i}\right)
$$

with:

$\mathrm{Z}\left(\mathrm{s}_{i}\right)=$ the measured value at the $\mathrm{i}^{\text {th }}$ location

$\lambda_{i}=$ an unknown weight for the measured value at the $\mathrm{i}^{\text {th }}$ location

$\mathrm{s}_{0}=$ the prediction location

$\mathrm{N}=$ the number of measured values

The output of the spatial kriging analysis was a statistically predicted VKT surface for each of the 24 cities, which in turn facilitated the generalized linear model regression analysis at the block group level of geography. Figure 4 illustrates the results of the spatial kriging in a VKT surface prediction map for one of the cities, San Mateo, California. With this research, the overarching question we are trying to answer is the following: How are community designs, in terms of street network, street design, and land use measures, correlated with vehicle kilometers traveled? Thus, the following generalized linear regression equation establishes the estimated number of vehicle kilometers traveled per person (18 years or older) per day:

$$
\mathrm{Y}=\mathrm{b}_{0}+\mathrm{b}_{1} \mathrm{X}_{1}+\mathrm{b}_{2} \mathrm{X}_{2}+\ldots+\mathrm{b}_{k} \mathrm{X}_{k}
$$

where:

$$
\begin{aligned}
& \mathrm{Y}=\text { dependent variable } \\
& \mathrm{b}_{0}=\text { constant } \\
& \mathrm{b}_{1} \ldots \mathrm{b}_{k}=\text { regression coefficients } \\
& \mathrm{X}_{1} \ldots \mathrm{X}_{k}=\text { independent predictor variables } \\
& \mathrm{k}=\text { number of predictor variables }
\end{aligned}
$$


Using a multiple regression model, we investigated the statistical relationship between VKT and community design measures including street network density, street connectivity, street configuration, street design, and the degree of mixed land uses. We also tested and analyzed interactions among selected community design variables; more specifically, we tested interactions among density, connectivity, configuration, and the number of lanes on the citywide streets. Variables controlled for in our models included proximity to limited access highways and income. Because of the relative magnitude of the average income variable compared to other variables, income was scaled and standardized to range from 0 to 1 so that the statistical coefficients could be estimated and the direction of the effect could be observed. As part of the analysis, the following community design variables were tested but not used in our final models because they showed high correlation with other variables that were tested:

- Population

- Population Density

- Employment Density

- Mode Share Data
- Average Travel Time to Work

- Centerline Kilometers (Miles) of Streets

- Centerline Kilometers (Miles) of Streets per Square Kilometer (Square Mile)

- Percent of Streets by Type

- Connected Node Ratio

- Average Block Size

- Curb-to-Curb Distance

- Percent of Citywide Street Length with Sidewalks

\section{$5 \quad$ Results}

The results from the multiple regression analysis are shown in Table 2. Overall, the results suggest that the way we build our communities - in terms of factors such as network layout, street design, and land use - correlate with the amount of driving people do each day. The significant variables included street network density, street connectivity, and major road design factors such as the number of lanes, outside shoulders, raised medians and the presence of on-street parking, bike lanes, and curbs/sidewalks. The degree of mixed land use in the vicinity

\begin{tabular}{|c|c|c|c|c|}
\hline & Mean & S.D. & Minimum & Maximum \\
\hline \multicolumn{5}{|l|}{ Dependent Variable } \\
\hline $\begin{array}{l}\text { VKT per person }(\geq 18) \text { per day (kilometers) } \\
\text { (VMT in miles) }\end{array}$ & $\begin{array}{r}35.21 \\
(21.88)\end{array}$ & $\begin{array}{r}6.30 \\
(3.91)\end{array}$ & $\begin{array}{r}0 \\
(0)\end{array}$ & $\begin{array}{r}52.81 \\
(32.81)\end{array}$ \\
\hline \multicolumn{5}{|l|}{ Street Network Design Variables } \\
\hline $\begin{array}{r}\text { Intersection Density (intersections / sq. km.) } \\
\text { (intersections / sq. mi.) }\end{array}$ & $\begin{array}{r}68.0 \\
(176.0)\end{array}$ & $\begin{array}{r}38.1 \\
(98.8)\end{array}$ & $\begin{array}{r}3.1 \\
(7.9)\end{array}$ & $\begin{array}{r}215.8 \\
(559.0)\end{array}$ \\
\hline Dead End Density (dead ends / sq. km.) & 12.4 & 10.7 & 0 & 80.7 \\
\hline (dead ends / sq. mi.) & $(32.0)$ & $(27.7)$ & $(0)$ & $(209.0)$ \\
\hline Major Road Intersection Density (major int. / sq. km.) & 23.2 & 26.6 & 0 & 201.9 \\
\hline (major int. / sq. mi.) & $(60.1)$ & $(68.8)$ & $(0)$ & $(523.0)$ \\
\hline Link to Node Ratio (\# links / \# intersections) & 1.20 & 0.20 & 0.40 & 2.00 \\
\hline Curvilinear $(0,1)$ & 0.20 & 0.40 & 0 & 1 \\
\hline \multicolumn{5}{|l|}{ Land Use Variables } \\
\hline Degree of Mixed Land Uses & 0.45 & 0.05 & 0.31 & 0.53 \\
\hline Distance from City Center (km) & 2.9 & 2.3 & 0 & 14.5 \\
\hline (miles) & $(1.8)$ & $(1.4)$ & $(0.0)$ & $(9.0)$ \\
\hline Bisecting or Adjacent Limited Access Highway $(0,1)$ & 0.30 & 0.40 & 0 & 1 \\
\hline \multicolumn{5}{|l|}{ Street Design Variables for Citywide Streets } \\
\hline Avg. Total Number of Lanes & 3.0 & 1.1 & 0 & 7.0 \\
\hline Avg. Outside Shoulder Width (meters) & 0.5 & 0.8 & 0 & 3.7 \\
\hline (feet) & $(1.7)$ & $(2.6)$ & $(0)$ & $(12.0)$ \\
\hline$\%$ of Citywide Street Length with Raised Median & 0.50 & 0.50 & 0 & 1 \\
\hline$\%$ of Citywide Street Length with Painted Median & 0.40 & 0.50 & 0 & 1 \\
\hline$\%$ of Citywide Street Length with On-Street Parking & 0.50 & 0.40 & 0 & 1 \\
\hline$\%$ of Citywide Street Length with Bike Lanes & 0.30 & 0.30 & 0 & 1 \\
\hline$\%$ of Citywide Street Length with Curbs & 0.80 & 0.30 & 0 & 1 \\
\hline \multicolumn{5}{|l|}{ Miscellaneous } \\
\hline Income & $\$ 57,268$ & $\$ 21,549$ & $\$ 11,956$ & $\$ 128,223$ \\
\hline Income standardized from 0 to 1 & 0.40 & 0.20 & 0 & 1 \\
\hline
\end{tabular}

Table 1 Summary statistics of variables at the census block group level. 


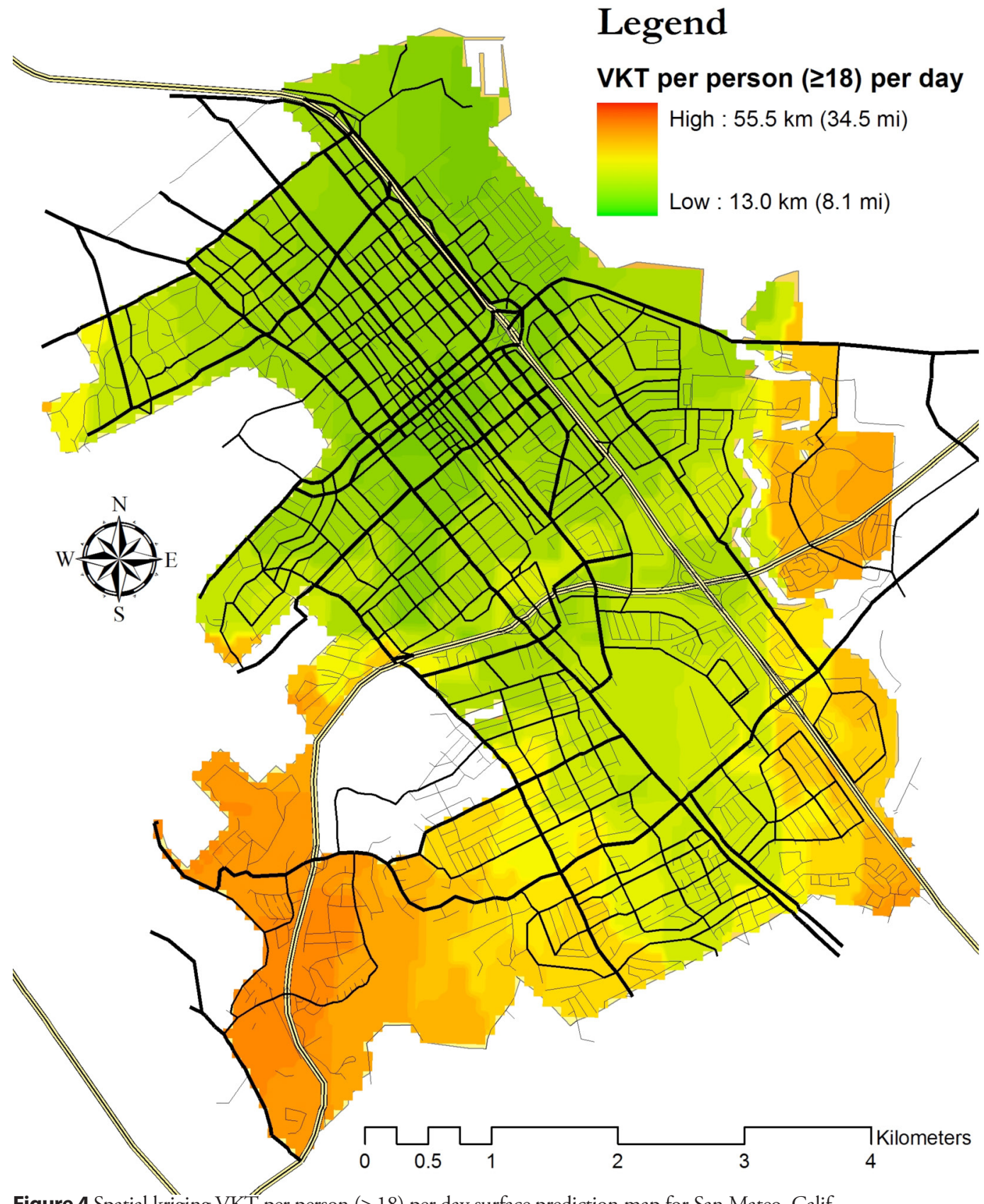

Figure 4 Spatial kriging VKT per person ( $\geq 18$ ) per day surface prediction map for San Mateo, Calif.

of a block group was also significantly correlated with VKT as were the distance of the block group to the city center and whether or not a limited access highway bisects or runs adjacent to a block group. Some street configuration types were significant in addition to a number of interaction terms that combine street pattern classification, intersection density, the link-to-node ratio, and the average number of lanes. Due to these interaction terms, interpreting the results directly from Table 2 can be complicated. In an effort to clarify the results of the statistical model, we focus on the change in VKT per per- son per day predicted by the models based on discrete changes to individual variables. This approach enables us to hold all variables at their mean and observe how VKT would change if a single variable, such as street connectivity, was changed. The results in Table 3 were calculated for the six most frequently occurring street patterns.

To further clarify Table 3, along the top row of this table is the VKT predicted for each of the six most common street network configuration types based on the mean value of all the variables given that particular configuration type. In other 
words, if we consider the average fully gridded street network (configuration type 'GG' with both gridded citywide and neighborhood streets), we would expect the average adult living in such a place to be driving 30.9 kilometers (19.2 miles) per day, as shown in the top right-hand corner of Table 3 . Table 3 then goes on to present the predicted VKT value if we were, for example, to change the overall intersection density (i.e., street network density) from 31.3 to 55.6 to 86.9 to 125 intersections per square-kilometer (81 to 144 to 225 to 324 intersections per square mile, which corresponds to the number of intersections that would be found in hypothetical 9x9, 12x12, 15x15, and $18 \times 18$ square-mile grids) while holding all the other variables at their mean value. For this example, the results suggest that VKT per person per day would increase by 44.8 percent if intersection density decreased from the average value for a typical fully gridded configuration to 31.3 intersections per square kilometer (81 int./mi2). Accordingly, increasing intersection density from 31.3 to 125 intersections per square kilometer (81 to $325 \mathrm{int} . / \mathrm{mi} 2$ ) is associated with a decrease in VKT per person per day from $44.7 \mathrm{~km}$ (27.8 mi.) to $26.5 \mathrm{~km}$ (16.5 mi.). Noland and Quddus, among others, presented results from a statistically based paper in a similar fashion and point out that the results are mathematically equivalent to elasticity values, but the methodology helps make the findings more useful and accessible (Noland and Quddus 2004).

Higher intersection density consistently reduced VKT for every street configuration, and interestingly, although the effect was comparatively smaller, higher street connectivity-with all other variables held at their mean-correlated with increased VKT. By averaging the VKT values for each of the six configuration types, we find that VKT drops quite drastically from 41.8 kilometers (26.0 miles) per day to less than 28 kilometers (17.4 miles) per day when going from the lowest density category to the highest with all other variables held at their mean value. This trend holds for all six configurations, with the fully gridded type "GG" finding the largest effect. This result suggests that in terms of reducing driving, increased street network density can make more of a difference in communities where there is already good street connectivity in place at the neighborhood level.

At the same time, increasing street connectivity from the lowest threshold to the highest brings average VKT per day from 33.4 to 36.6 kilometers (20.8 to 22.7 miles) with similar results for each of the six configurations. While we did not expect to find increased street connectivity correlated with more VKT, the idea that increasing connectivity might have a slightly adverse effect on VKT is not implausible, especially given the fact that one of the current limitations of the street network measures in this analysis is the focus on vehicle connectivity.
For many of the 24 cities in the database, the pedestrian and bicyclist network are different from the vehicle network. For instance, while Berkeley's layout primarily reflects the gridded network type "GG," design adaptations such as the "Berkeley Barriers" restrict through movements at certain intersection for cars but allow them for other modes. These modifications to the grid are accounted for similar to dead ends in terms of the link-to-node ratio even though they permit pedestrian and bicyclist connectivity. Another example is the Village Homes area in Davis, where a dendritic vehicle street network is augmented by a fully connected pedestrian and bicyclist path network. Because of the difficulty in acquiring the path networks for all 24 cities, these pedestrian and bicyclist networks have not yet been fully accounted for; thus, a higher link-to-node ratio indicates more connectivity for vehicles, which, given the limitations of the data, could hypothetically increase VKT levels. Also, street connectivity in itself might not be as important in lowering VKT as connectivity between typical origins and destinations; however, we should not rule out the possibility that increasing street connectivity in itself is correlated with more VKT in certain situations and an issue that warrants further study.

We also tested the relative mix of different intersection types within a community in terms of major road intersection density (using the citywide streets) and dead end density. While dead end density was not significant in the model, we found that increasing major road intersection density (i.e., the abundance of citywide streets intersecting one another) increases the amount of driving by approximately 1.3 kilometers ( 0.8 miles) per person per day. This result suggests that a network with a high number of what would be considered major intersections — and accordingly, major roads—can hinder walking, biking, and transit use.

The statistical models have thus far presented us with a couple of basic results concerning community design in terms of the street network: first, increased street density in the form of intersection density was correlated with decreased VKT; and second, increased street connectivity in the form of the link-tonode ratio was associated with increased VKT, but to a lesser degree. These results seem to suggest that if our only goal in design is to decrease VKT, we could plan for our places to be both dense and unconnected for vehicles. The challenge is that real places are a combination of complementary design factors. As such, it is important to consider the statistical results in the context of how communities are actually built and how people use them. For instance, configuration type was significant in some respect for most patterns shown in Table 3. Looking across Table 3, we can begin to compare the influence of pattern type on the amount of driving people did on a day-to-day basis; however, a direct comparison is difficult since each of 
these layouts is, in practice, built at different densities with a wide range of complementary features. So when comparing VKT results with respect to the street pattern classifications, it is important to understand that individual configurations are often built with different complementary features such as higher densities, fewer lanes on the major roads, or a more complete sidewalk network. Keeping that in mind, the manner in which the three configurations with a gridded neighborhood street system are built in practice tended to result in lower VKT per person per day than the three configurations with tree-like neighborhood streets. In fact, average VKT for the tree-like neighborhood networks was approximately 18 percent higher than the average for the gridded neighborhood networks. Because of complementary features, such as fewer lanes on the major roads, lower VKT held for the gridded neighborhood streets even though they also tended to exhibit higher street connectivities, which in itself would normally be associated with higher VKT.

When looking in more detail at the difference between the three gridded neighborhood networks depicted in Table 3, the residents of the first one-tributary citywide streets and gridded neighborhood streets pattern type ("TG")—drove approximately 1.9 more kilometers $(1.2$ miles) per day than in the other two gridded neighborhood patterns shown. Inspecting these street patterns highlights the fact that pattern type "TG" likely has far fewer opportunities for moving between the neighborhood and citywide streets, even though the overall street connectivity measures seem similar.

Another variable related to street configuration was whether the street networks exhibited curvilinearity. The results suggest that curvilinear streets tended to increase VKT by about 1.8 kilometers $(1.1$ miles) per person per day. This was expected, as curvilinear streets tend to decrease directness and increase distances along roads, which could be responsible for the slight increase in VKT. Also, curvilinear streets might be indicative of hilly terrains, which could also negatively impact walking and biking.

Street design features were also considered. These features included the total number of lanes and outside shoulder width, as well as the presence of bike lanes, curbs or sidewalks, and the presence of raised and painted medians. Overall, more lanes on the citywide streets, increased shoulder width, and less on-street parking were associated with increased VKT. Such features tend to result in major roads designed more like highways, which would likely promote a built environment most suitable for driving. Generally, these factors were correlated with VKT changes between 0.5 and 2 kilometers $(0.3$ and 1.2 miles) per person per day. For instance, the presence of on-street parking - which has been shown in other studies to reduce vehicle speeds and promote more walking and biking-decreased VKT by, on average, 1 kilometer (0.6 miles) per person per day (Marshall, Garrick et al. 2008). The one street design factor that was associated with a much greater difference in VKT was the number of lanes on the citywide streets. On average, adding a lane in each direction on the main roads was correlated with an average increase of 7.5 kilometers (4.7 miles) per person per day. Living in an area with wide, more highway-like major roads might be beneficial in terms of reducing congestion, but these same roads also can become a barrier to walking and biking.

Other significant variables included the distance of a block group to the city center, the proxy for the degree of mixed land use, and whether a limited access highway bisects or is adjacent to a block group. All three of these variables exhibited the expected results in our statistical model. For instance, the further a block group is from the city center, the more driving per capita. In terms of a block group showing signs of mixed use in the block group itself or in the surrounding vicinity, people living in an area with a high degree of mixed land uses drove about 1.8 fewer kilometers (1.1 fewer miles) per day. As for adjacency to a limited access highway, this correlated to increased VKT. While being near a highway might increase directness on longer distance trips, it can also serve as a barrier that lengthens what would be shorter trips while also negatively impacting walking and biking.

\subsection{Discussion}

Even relatively small daily VKT reductions are extremely promising, especially when considered over a longer period of time across a population. For instance, over the course of a year in a city with a population of 60,000 , which is approximately the average size for the cities in our study, a drop in VKT of a single kilometer driven per person per day would result in a net decrease of 21.9 million kilometers (13.6 million miles) driven each year. Accordingly, a reduction in driving by a single kilometer per person per day would save 2.5 million liters of gasoline annually, which could help save millions of dollars and prevent more than 12 million $\mathrm{lb}$. of $\mathrm{CO}_{2}$ from being emitted into the atmosphere each year in a single city, or the equivalent of removing more than 1,000 cars from the road for a full year ${ }^{1}$ (Environmental Protection Agency 2005). The key point is that community design can go a long way toward considerably

1 Calculations based on current average California gas prices as well as EPA guidelines for calculating emissions, including an average fleet efficiency of 8.6 kilometers per liter $(20.3 \mathrm{mpg})$ and that each liter of gasoline used accounts for $5.1 \mathrm{lb}$. of $\mathrm{CO}_{2}$. Environmental Protection Agency, 2005. Emission Facts: Greenhouse Gas Emissions from a Typical Passenger Vehicle. Washington, DC. PA420-F-05-004. 
Table 2 Multiple regression VKT model

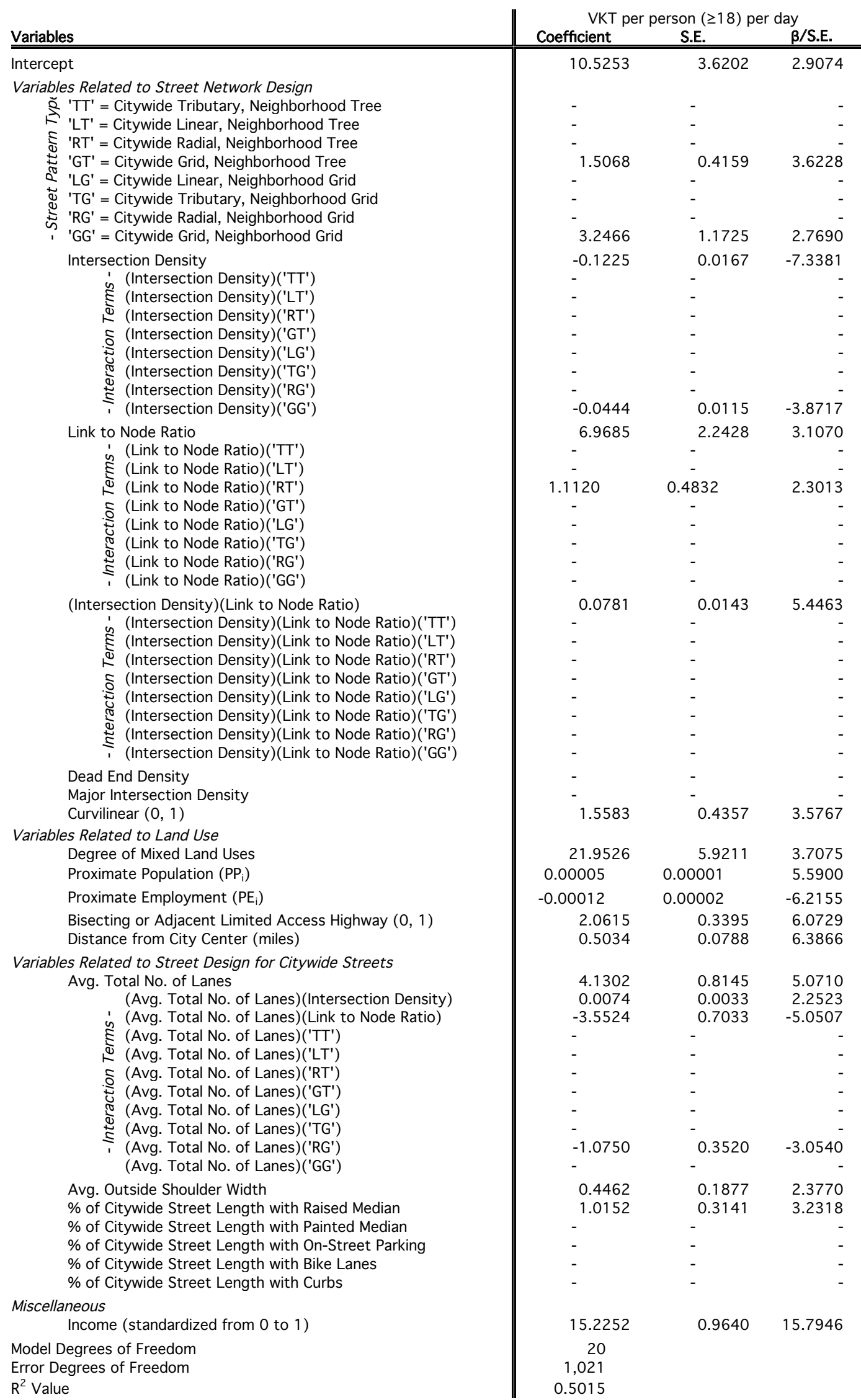




\begin{tabular}{|c|c|c|c|c|c|c|c|c|c|c|c|c|c|c|}
\hline $\begin{array}{l}\text { Base VKT per person }(\geq 18) \text { per day } \\
\text { by Street Network Configuration }(\mathrm{km}) \text { : }\end{array}$ & & & & & \multicolumn{2}{|c|}{ 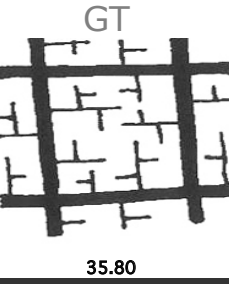 } & & & \multicolumn{2}{|c|}{31.48} & & & $\begin{array}{r}\text { Aver } \\
3\end{array}$ & $\begin{array}{l}\mathrm{VKT} \\
9\end{array}$ \\
\hline \multicolumn{3}{|c|}{ Intersection Density (i.e. Street Network Density) } & & & & & & & & & & & & \\
\hline $31.3 \mathrm{int} / \mathrm{km}^{2}\left(81 \mathrm{int} / \mathrm{mi}^{2}\right)$ & 39.69 & $8.56 \%$ & 42.83 & $6.49 \%$ & 40.00 & $11.73 \%$ & 40.77 & $23.25 \%$ & 42.53 & $35.10 \%$ & 44.71 & $44.79 \%$ & 41.76 & $21.76 \%$ \\
\hline $55.6 \mathrm{int} / \mathrm{km}^{2}\left(144 \mathrm{int} / \mathrm{mi}^{2}\right)$ & 36.35 & $-0.57 \%$ & 39.48 & $-1.84 \%$ & 36.66 & $2.40 \%$ & 37.43 & $13.15 \%$ & 39.18 & $24.46 \%$ & 39.98 & $29.47 \%$ & 38.18 & $11.34 \%$ \\
\hline $86.9 \mathrm{int} / \mathrm{km}^{2}\left(225 \mathrm{int} / \mathrm{mi}^{2}\right)$ & 32.04 & $-12.36 \%$ & 35.18 & $-12.53 \%$ & 32.35 & $-9.64 \%$ & 33.13 & $0.15 \%$ & 34.88 & $10.80 \%$ & 33.90 & $9.78 \%$ & 33.58 & $-2.08 \%$ \\
\hline 125 int $/ \mathrm{km}^{2}\left(324 \mathrm{int} / \mathrm{mi}^{2}\right)$ & 26.79 & $-26.72 \%$ & 29.92 & $-25.61 \%$ & 27.10 & $-24.30 \%$ & 27.87 & $-15.75 \%$ & 29.62 & $-5.91 \%$ & 26.48 & $-14.25 \%$ & 27.96 & $-18.46 \%$ \\
\hline \multicolumn{15}{|l|}{ Citywide Streets Intersection Density } \\
\hline $7.7 \mathrm{int} / \mathrm{km}^{2}\left(20 \mathrm{int} / \mathrm{mi}^{2}\right)$ & 36.47 & $-0.25 \%$ & 40.17 & $-0.12 \%$ & 35.56 & $-0.67 \%$ & 32.48 & $-1.81 \%$ & 30.44 & $-3.30 \%$ & 29.59 & $-4.18 \%$ & 34.12 & $-0.51 \%$ \\
\hline $23.2 \mathrm{int} / \mathrm{km}^{2}\left(60 \mathrm{int} / \mathrm{mi}^{2}\right)$ & 36.90 & $0.93 \%$ & 40.60 & $0.94 \%$ & 35.98 & $0.50 \%$ & 32.91 & $-0.51 \%$ & 30.86 & $-1.97 \%$ & 30.01 & $-2.82 \%$ & 34.54 & $0.73 \%$ \\
\hline $38.6 \mathrm{int} / \mathrm{km}^{2}\left(100 \mathrm{int} / \mathrm{mi}^{2}\right)$ & 37.32 & $2.08 \%$ & 41.02 & $1.99 \%$ & 36.40 & $1.68 \%$ & 33.33 & $0.76 \%$ & 31.29 & $-0.60 \%$ & 30.44 & $-1.42 \%$ & 34.97 & $1.97 \%$ \\
\hline $54.1 \mathrm{int} / \mathrm{km}^{2}\left(140 \mathrm{int} / \mathrm{mi}^{2}\right)$ & 37.74 & $3.23 \%$ & 41.44 & $3.03 \%$ & 36.83 & $2.88 \%$ & 33.75 & $2.03 \%$ & 31.71 & $0.73 \%$ & 30.86 & $-0.06 \%$ & 35.39 & $3.20 \%$ \\
\hline \multicolumn{15}{|c|}{ Link to Node Ratio (i.e. Street Connectivity) } \\
\hline $1.1-1$ & 36.18 & $-1.04 \%$ & 39.59 & $-1.57 \%$ & 34.79 & $-2.82 \%$ & 31.58 & $-4.53 \%$ & 29.49 & $-6.32 \%$ & 28.62 & $-7.32 \%$ & 33.38 & $-2.67 \%$ \\
\hline 1.25 & 37.29 & $2.00 \%$ & 40.70 & $1.19 \%$ & 35.91 & $0.31 \%$ & 32.51 & $-1.72 \%$ & 30.60 & $-2.80 \%$ & 29.74 & $-3.69 \%$ & 34.46 & $0.49 \%$ \\
\hline 1.4 & 38.41 & $5.06 \%$ & 41.82 & $3.98 \%$ & 37.02 & $3.41 \%$ & 33.45 & $1.12 \%$ & 31.72 & $0.76 \%$ & 30.85 & $-0.10 \%$ & 35.55 & $3.65 \%$ \\
\hline 1.55 & 39.53 & $8.12 \%$ & 42.94 & $6.76 \%$ & 38.14 & $6.54 \%$ & 34.38 & $3.93 \%$ & 32.84 & $4.32 \%$ & 31.97 & $3.53 \%$ & 36.63 & $6.83 \%$ \\
\hline \multicolumn{15}{|l|}{ Curvilinear Street Network $(0,1)$} \\
\hline 0 & 36.07 & $-1.34 \%$ & 39.23 & $-2.46 \%$ & 35.66 & $-0.39 \%$ & 32.95 & $-0.39 \%$ & 31.41 & $-0.22 \%$ & 30.88 & $0.00 \%$ & 34.37 & $0.22 \%$ \\
\hline 1 & 37.84 & $3.50 \%$ & 40.99 & $1.91 \%$ & 37.42 & $4.53 \%$ & 34.71 & $4.93 \%$ & 33.18 & $5.40 \%$ & 32.65 & $5.73 \%$ & 36.13 & $5.36 \%$ \\
\hline \multicolumn{15}{|c|}{ Avg. No. of Lanes on Citywide Streets } \\
\hline 2 & 33.11 & $-9.44 \%$ & 34.54 & $-14.12 \%$ & 30.84 & $-13.85 \%$ & 29.47 & $-10.91 \%$ & 30.16 & $-4.19 \%$ & 27.70 & $-10.30 \%$ & 30.97 & $-9.69 \%$ \\
\hline 4 & 41.11 & $12.45 \%$ & 42.55 & $5.79 \%$ & 38.85 & $8.52 \%$ & 37.48 & $13.30 \%$ & 35.03 & $11.28 \%$ & 35.70 & $15.61 \%$ & 38.45 & $12.13 \%$ \\
\hline 6 & 49.12 & $34.35 \%$ & 50.55 & $25.68 \%$ & 46.85 & $30.87 \%$ & 45.48 & $37.48 \%$ & 39.91 & $26.78 \%$ & 43.70 & $41.52 \%$ & 45.94 & $33.95 \%$ \\
\hline \multicolumn{15}{|c|}{ Block Group Distance from City Center } \\
\hline $0.8 \mathrm{~km}(0.5 \mathrm{mi})$. & 35.23 & $-3.64 \%$ & 37.63 & $-6.44 \%$ & 34.74 & $-2.96 \%$ & 32.45 & $-1.90 \%$ & 30.75 & $-2.32 \%$ & 30.52 & $-1.17 \%$ & 33.55 & $-2.15 \%$ \\
\hline $3.2 \mathrm{~km}(2.0 \mathrm{mi})$. & 36.51 & $-0.14 \%$ & 38.92 & $-3.23 \%$ & 36.02 & $0.61 \%$ & 33.74 & $2.00 \%$ & 32.03 & $1.75 \%$ & 31.80 & $2.98 \%$ & 34.84 & $1.59 \%$ \\
\hline $5.6 \mathrm{~km}(3.5 \mathrm{mi})$. & 37.80 & $3.39 \%$ & 40.20 & $-0.05 \%$ & 37.30 & $4.19 \%$ & 35.02 & $5.86 \%$ & 33.32 & $5.84 \%$ & 33.08 & $7.12 \%$ & 36.12 & $5.33 \%$ \\
\hline $8.0 \mathrm{~km}(5.0 \mathrm{mi})$. & 39.08 & $6.89 \%$ & 41.48 & $3.13 \%$ & 38.58 & $7.77 \%$ & 36.30 & $9.73 \%$ & 34.60 & $9.91 \%$ & 34.37 & $11.30 \%$ & 37.40 & $9.07 \%$ \\
\hline \multicolumn{15}{|l|}{ Degree of Mixed Land Use } \\
\hline Low $(0.3)$ & 38.03 & $4.02 \%$ & 41.51 & $3.21 \%$ & 36.94 & $3.18 \%$ & 34.40 & $3.99 \%$ & 32.87 & $4.42 \%$ & 32.36 & $4.79 \%$ & 36.02 & $5.03 \%$ \\
\hline Medium (0.4) & 37.10 & $1.48 \%$ & 40.59 & $0.92 \%$ & 36.02 & $0.61 \%$ & 33.48 & $1.21 \%$ & 31.95 & $1.49 \%$ & 31.44 & $1.81 \%$ & 35.10 & $2.35 \%$ \\
\hline High $(0.5)$ & 36.18 & $-1.04 \%$ & 39.67 & $-1.37 \%$ & 35.10 & $-1.96 \%$ & 32.56 & $-1.57 \%$ & 31.03 & $-1.43 \%$ & 30.51 & $-1.20 \%$ & 34.18 & $-0.34 \%$ \\
\hline \multicolumn{15}{|c|}{ Bisecting or Adjacent to Limited Access Highway $(0,1)$} \\
\hline 0 & 35.89 & $-1.83 \%$ & 39.75 & $-1.17 \%$ & 35.37 & $-1.20 \%$ & 32.43 & $-1.96 \%$ & 31.18 & $-0.95 \%$ & 30.53 & $-1.13 \%$ & 34.19 & $-0.29 \%$ \\
\hline & 37.85 & $3.53 \%$ & 41.71 & $3.70 \%$ & 37.33 & $4.27 \%$ & 34.39 & $3.96 \%$ & 33.14 & $5.27 \%$ & 32.49 & $5.21 \%$ & 36.15 & $5.42 \%$ \\
\hline \multicolumn{15}{|c|}{$\%$ of Citywide Street Length with On-Street Parking } \\
\hline $0 \%$ & 36.94 & $1.04 \%$ & 40.51 & $0.72 \%$ & 36.28 & $1.34 \%$ & 33.59 & $1.54 \%$ & 32.22 & $2.35 \%$ & 31.69 & $2.62 \%$ & 35.21 & $2.66 \%$ \\
\hline $50 \%$ & 36.45 & $-0.30 \%$ & 40.01 & $-0.52 \%$ & 35.78 & $-0.06 \%$ & 33.09 & $0.03 \%$ & 31.72 & $0.76 \%$ & 31.19 & $1.00 \%$ & 34.71 & $1.21 \%$ \\
\hline $100 \%$ & 35.95 & $-1.67 \%$ & 39.51 & $-1.77 \%$ & 35.29 & $-1.42 \%$ & 32.60 & $-1.45 \%$ & 31.22 & $-0.83 \%$ & 30.69 & $-0.62 \%$ & 34.21 & $-0.24 \%$ \\
\hline
\end{tabular}


reducing VKT, funds spent on transportation, use of nonrenewable resources such as gasoline, and carbon emissions.

One possible explanation as to why community design and the way we build our cities affects VKT is that street networks and land uses influence opportunities to walk, bike, and take transit. We investigated the extent to which mode choice was a factor in the VKT outcomes by calculating the Pearson correlation coefficients and looking at whether the VKT reductions shown can be solely attributed to mode shift. The Pearson correlation coefficients for VKT per person per day in each block group to each of the corresponding 2000 Census mode shares are as follows:

\begin{tabular}{ccccc}
\hline & Driving & Walking & Bicycling & Transit \\
\hline VMT & 0.494 & -0.354 & -0.271 & -0.427
\end{tabular}

These results suggest that VKT is moderately correlated with driving, walking, and transit and less so with bicycling, which indicates that shifts from driving to transit and active transport modes seem to be accounting for only a part of the overall VKT reduction. Another factor in explaining the VKT reductions could be that the denser street networks provide closer destinations and more directness of travel—resulting in fewer kilometers driven for people on a day-to-day basis.

\section{Conclusion}

The results from the 24 California cities show that residents of the denser communities with more mixed land uses drive fewer kilometers per day than those living in sparser, more homogenous areas. Increased street connectivity also resulted in increased VKT; however, our street connectivity measure focused on connectivity for vehicles and did not consider the relative connectivity of actual origins and destinations. Also, the overall results suggest that in terms of reducing driving, increased street network density can make much more of a difference where there is already good street connectivity in place at the neighborhood level.

The way that communities are laid out in terms of street configurations was also significant in the amount of driving people did on a day-to-day basis, for which we found that pattern types with gridded neighborhood streets tended to result in lower VKT per person per day than those with tree-like neighborhood streets. It is important to keep in mind that each of these street network measures needs to work in concert as pieces of a larger overall puzzle that also includes factors such as street design and land use. For instance, while higher street connectivity was associated with higher VKT, other features that tended to be in the more connected configurations also tended to lend themselves to lower driving rates; more specifically, the average VKT for the communities with neighborhoods exhibiting a more tree-like network structure was approximately 18 percent higher than the places with more gridded neighborhood designs. Overall, the results suggest that the lower VKT for people living in such places tended to be partially due to more walking, biking, and transit use but also partly due to closer destinations and more directness of travel.

While we took into account as many factors as feasible for this study-including street design characteristics, street features, the presence of a bike lanes and sidewalks, the mix of land uses, and income-there are always other issues to consider: link speed, intersection controls, the connectivity and attractiveness of the bike and pedestrian environment, and social and cultural factors, for instance. Future survey work will consider such attitudinal questions in order to account for issues such as self-selection.

The fundamental premise is that community design and the way we build our places plays a key role in efficiency and performance. In terms of community design, increased street network density has a synergistic effect, both in creating opportunities for active transportation and in making shorter and more efficient car trips possible. This synergistic effect is worthy of further examination as to the potential for reducing VKT, which could lead to a more complete understanding of how such layouts and features cooperate toward the goal of building places better able to facilitate the sustainability goals we are looking to achieve.

\section{References}

Bartholomew, K. and R. Ewing. 2009. Land-use transportation scenarios and future vehicle travel and land consumption: A meta-analysis. Journal of the American Planning Association, $75(1)$ : 13-27.

Cervero, R. and R. Gorham. 1995. Commuting in transit versus automobile neighborhoods. Journal of the American Planning Association, 61(2): 210-225.

Cervero, R. and K. Kockelman 1997. Travel demand and the 3 ds: Density, diversity, and design. Transportation Research Part D: Transport and Environment, 2(3): 199-219.

Crane, R., 1996. Cars and drivers in the new suburbs: Linking access to travel in neotraditional planning. Journal of the American Planning Association, 62: 51-65. 
Crane, R. and R. Crepeau. 1998. Does neighborhood design influence travel? Behavioral analysis of travel diary and GIS data. http://www.uctc.net/papers/374.pdf.

Curtis, F., L. Neilsen, et al. 1984. Impact of residential street design on fuel consumption. Journal of Urban Planning and Development, 110: 1-8.

Environmental Protection Agency, 2005. Emission Facts: Greenhouse Gas Emissions from a Typical Passenger Vehicle. Washington, DC. PA420-F-05-004.

Ewing, R., 1996. Best Development Practices: Doing the Right Thing and Making Money at the Same Time. Washington, DC: APA Planners Press.

Ewing, R., R. Pendall, et al. 2003. Measuring Sprawl and its transportation impacts. Transportation Research Record, 1832: 175-193.

Frank, L. D., B. Stone Jr., and W. Bachman. 2000. Linking land use with household vehicle emissions in the central puget sound: methodological framework and findings. Transportation Research Part D, 5(3): 173-196.

Graham, D. and S. Glaister. 2003. Spatial variation in road pedestrian casualties: The role of urban scale, density and land-use mix. Urban Studies, 40(8): 1591-1607.

Handy, S., R. Paterson, et al. 2003. Planning for Street Connectivity: Getting from Here to There. Planning Advisory Service Report 515, American Planning Association.

Heres-Del-Valle, D. and D. Niemeier. 2011. CO2 emissions: Are land-use changes enough for California to reduce VMT? Specification of a two-part model with instrumental variables. Transportation Research Part B, 41(1): 150-161.

Hillier, B. and J. Hanson. 1984. The Social Logic of Space. New York: Cambridge University Press.

Holtzclaw, J., 1994. Using Residential Patterns and Transit to Decrease Auto Dependence and Costs. San Francisco, Natural Resources Defense Council.

Jiang, B. and C. Claramunt. 2004. A structural approach to the model generalization of an urban street network. GeoInformatica, 8(2): 157-171.
Kulash, W., 1990. Traditional neighborhood development: Will the traffic work? URL http://user.gru.net/domz/kulash.htm.

Litman, T., 2005. Roadway Connectivity: Creating More Connected Roadway and Pathway Networks. URL http:// www.vtpi.org/tdm/tdm116.htm.

Marshall, S., 2005. Streets \& Patterns. New York: Spon Press.

Marshall, W., N. Garrick, et al., 2008. Reassessing on-street parking. Transportation Research Record, 2046: 45-52.

Mindali, O., A. Raveh, et al. 2004. Urban density and energy consumption: a new look at old statistics. Transportation Research Part A, 38: 143-162.

Moeller, D. 1992. Environmental Health. Cambridge, MA: Harvard University Press.

Newman and Kentworthy. 1989. Cities and Automobile Dependence. Brookfield, VT: Gower.

Noland, R. and M. Quddus. 2004. A spatially disaggregate analysis of road casualties in England. Accident Analysis and Prevention, 36(6): 973-984.

Oliver, M., 1990. Kriging: A method of interpolation for geographical information systems. International Journal of Geographic Information Systems, 4: 312-332.

Peponis, J., D. Allen, et al. 2007. Measuring the configuration of street networks: the spatial profiles of 118 urban areas in the 12 most populated metropolitan regions in the U.S. 6th International Space Syntax Symposium, Istanbul, Turkey.

Portland Metro. 2004. Street Connectivity: An Evaluation of Case Studies in the Portland Region. URL http://library.oregonmetro.gov/files/connectivityreport.pdf.

Raford, N., A. Chiaradia, et al., 2007. Space Syntax: The Role of Urban Form in Cyclist Route Choice in Central London. Institute of Transportation Studies: UC Berkeley Traffic Safety Center.

Ratti, C., 2004. Space syntax: Some inconsistencies. Environment and Planning B: Planning and Design, 31: 487-499. 
Schrank, D. and T. Lomax, T. 2009. 2009 Urban Mobility Report, Texas Transportation Institute.

Southworth, M. and E. Ben-Joseph.1997. Street and the Shaping of Towns and Cities. New York: McGraw-Hill.

Su, Q., 2010. Travel demand in the US urban areas: A system dynamic panel data approach. Transportation Research Part A, 44(2): 110-117.

Taylor, J., 2001. Transportation and community design: The effects of land use and street pattern on travel behavior. http://www.sustainable-communities.agsci.ubc.ca/bulletins/TB_issue_11_Transportation_edit.pdf.

U.S. Energy Information Administration. 2010. Petroleum Navigator. http://www.eia.doe.gov/. 